\title{
Information on IMIA Regional Groups
}

\section{APAMI \\ Asia Pacific Association for Medical Informatics}

\section{Membership of APAMI}

The currently active member societies include Australia (HISA), China (CMIA), Hong Kong SAR (HKSMI), India (IAMI), Japan (JAMI), Korea (KOSMI), New Zealand (HINZ), Philippines, Sri Lanka (HISSL), Singapore, Taiwan (TAMI) and Thailand (TMIA). There are observer members from Bangladesh, Indonesia, Malaysia and Nepal. Though Kazakhstan, Pakistan and Vietnam were members as per past reports, we have been unable to elicit any updates from them.

\section{General Assembly Meeting of APAMI}

The AGM for 2015 was held at in conjunction with MEDINFO 2015 in Sao Paulo Brazil on August 21, 2015. This meeting was attended by 9 member societies (Australia, China, Hong Kong, India, Japan, Korea, New Zealand, Singapore and Taiwan) with online attempts to join in from the Philippines. Some highlights of the AGM reports are:

a. APAMI shall continue to fund travel for attending APAMI as well as MEDINFO meetings for deserving members form the region. Tighter restrictions have however been enforced so that the payment are concomitant with actual costs.

b. The next APAMI biennial conference will be held in Seoul Korea in between November 3rd to 5th 2016. The GA will be held at the same time.

c. Ms Louise Schaper resigned as honorary secretary and Mr Klaus Veil, also from Australia, was co-opted into this position. We thank A/Prof Veil for taking up the job immediately. The official website of APAMI www.APAM-I.org has now been revamped and includes news updates and links to individual member organiza-tions' websites besides general information. We now also have a twitter news feed at www.twitter.com/ APAMInews

\section{APAMI Executive}

The APAMI leadership, consisting of the President, Imm Past President, Incoming President, Secretary and Treasurer) communicate regularly to transact the APAMI business.

The APAMI Executive uses the News@ APAMI.org e-mail list to facilitate inter-member communications which are showing regular activities and discussions.

\section{The Nepal Earthquake}

The Nepal quake in April 2015 elicited an active response with creation of special Help Nepal page on the APAMI website as well as personal visits to the affected areas by president S B Gogia.

\section{Member Participation in MEDINFO}

Efforts were made to ensure better participation of member states in MEDINFO as it was felt that paper acceptance rates were poorer than it could be.

\section{APAMI 2014 Attendance Support}

Bursaries were provided for 3 persons MEDINFO attendance bursaries are being provided for 4 persons from the APAMI region.

\section{MEDINFO Anniversary}

Michio Kimura is working with IMIA on the ,50th Anniversary of MEDINFO history project. He has requested support from all member organizations to provide input.

\section{APAMI Representation}

APAMIwas officially represented in the following meetings in 2015:

- HIMSS Asia Pacific India Chapter - Gurgaon, India in August 2015 (S B Gogia),

- HIMSS Asia Pacific - Singapore in September 2015 (Klaus Veil)

- Asia Pacific Telemedicine Conference Shanghai, China in November 2015 (S B Gogia)

\section{Members' Activities}

\section{Australia}

Klaus Veil, Australasian College of Health Informatics (ACHI) \& HISA

In May 2015, the Australian Government committed an additional $\mathrm{A} \$ 485.1 \mathrm{~m}$ to the enhancement and transition of the Personally Controlled Electronic Health Record (PCEHR) to a more usable ,My Health Record'. Currently, over $2.5 \mathrm{~m}$ Australians have, My Health Record' accounts, however a higher percentage of active records would be very much welcomed by clinicians. The first steps to achieve this are to test an ,opt-out' approach replacing the current opt-in registration procedure. Two trails will be held in the ,Blue Mountains" region near Sydney as well as in Northern Queensland. This activity will be lead by the new ,Australian Digital Health Agency“ (ADHA). As a result of the re-invigorated,My Health Record' development, a significant increase of Health ICT activities around Australia has been observed. This includes successful application ,hackathons' and interoperability ,connectathons" that were well-attended and attracted a lot of media publicity. There is also increased commercial activity of vendors supporting the eHealth systems implementation; some eHealth systems vendors have undertsken share market floats (Alcidion, Jayex, etc.) while others have consolidated into larger, well-funded corporations (Telsta Health).

The Council of Australian Governments (COAG) is planning a ,refresh ' of the 2008 National eHealth Strategy in early 2016. In general, a more evidence-based approach to Healthcare policy is being observed.

The HL7 FHIR standard, invented by Australian ACHI Fellow Grahame Grieve, is being adopted around the globe with astounding speed and has for many re-kindled the hope of finally achieving full interoperability of clinical information.

\section{China}

Lieping Wu, China Medical Informatics Association (CMIA)

CMIA has nothing special to report this year. In addition, CMIA has changed its representative from 2016. 


\section{Hong Kong}

C P Wong, Hong Kong Society of Medical Informatics (HKSMI)

The year of 2015 marks an important year for the development of eHealth in Hong Kong as the government finally approves the legal framework of the Territory Wide Electronic Health Records Sharing System Bill on 13 July 2015 at the Legislative Council. This means that we can officially establish the E H R office with the appointment of the Commissioner of Electronic Health Records in December and planning for a live run in late February 2016. This delay in Legislation has been on for 3 years and finally it has been passed. Tentatively, Hong Kong will enjoy a territory wide E H R Sharing between all private and public healthcare institution's records. This is subject to the voluntary opt-in participations from healthcare professionals and patients alike. The Society of Medical Informatics in Hong Kong, and the Hong Kong eHealth Consortium and the HL7 Hong Kong are working extremely hard together with the Hong Kong Hospital Authority to advocate the use of eHealth in Hong Kong. It is expected that the major breakthrough in the Sharing System will help to further enhance the efficiency and quality of healthcare delivery in Hong Kong. The Hong Kong Society of Medical Informatics continues to advocate health informatics education in Hong Kong. Partnering with the Hong Kong Polytechnic University, the Master of Science in Health Informatics and the Certificate course in Applied Health Informatics have attracted hundreds of IT and healthcare professionals. Partnering with the HKUSPACE, the Postgraduate Diploma in Health Informatics also continues to train dozens of students each year. We plan to host our regional Electronic Health Records Conference in the coming 6-7 July 2016 at the Science Park conference hall. An expected 800 delegates will participate and help boost up the atmosphere in the eHealth arena.

\section{India}

S B Gogia, Indian Association for Medical Informatics (IAMI)

After notifying the EHR standards in 2013 and purchase of a nationwide licence for SNOMED $\mathrm{CT}$, India is now progressing towards expanded and widespread usage of Electronic Health Records. A National eHealth Authority (NeHA) as well as provision of Tele-medicine services in various programs is part of the Digital India initiative planned by the BJP Government lead by Prime Minister Modi.

IAMI members have been assisting the government in its various efforts. IAMI has been engaged in various meetings to discuss the issues at hand. The prominent amongst these have been HIMSS Asia Pacific India Chapter Meeting in August and Health Informatics Summit, Mumbai in December as well launch of AHIMA India in October.

Ambient and interesting discussions are continuing in IAMIs various email forums like iami_gen@-googlegroups.com as well as iami@yahoogroups.com. Membership to the same is open to all across the globe. IAMI's own next biennial meeting is in February 26th to 18th, 2016. With elections under way a new team of office bearers will take charge after that.

\section{Japan}

Mihoko Okada, Japan Association for Medical Informatics (JAMI)

Collaborative Developments of Clinical Databases and Promotion of Standards

A number of clinical databases and patient registries are under development in Japan. Integration of clinical information collected from a number of clinical institutions with respective EMR/EHR systems to support analyses will require the use of standards. SS-MIX, which we reported last year, may be used for a variety of applications, and among them is patient registry. JAMI promotes the use of standards for clinical research including chronic kidney disease research in support for clinical database development by the Japanese So $\neg$ ciety of Nephrology. SSMIX sets the standards for messages (HL7 V2.5), patient demographics, prescription, and laboratory tests, with standard storage specification. It can facilitate new registry development by supporting well-defined data elements and data aggregation for research.

Collaborative Efforts for Data Interoperability and Health Informatics Infrastructure As reported last year, „Minimum Sets of Data Elements" for four lifestyle-related diseases and „Transferable Data from Personal Medical Records" have been jointly developed and rereleased by the Japan
Diabetes Society, the Japanese Society of Hypertension, the Japan Atherosclerosis Society, the Japanese Society of Nephrology and JAMI. www.jami.jp/english/document/ JAMI_HP_4itemset20150211-2.pd

JAMI set up collaborative committees with other Academic Associations and Organization. In collaboration with Japanese Society for Clinical Pathway, a committee was established to develop data models for clinical paths. With Japan Society for Problem Oriented System Healthcare and Japan Society of Health Information Management, a committee was established to develop patient summary standard and a problem list guideline. Chief Healthcare Information Officer is a theme that has been undertaken by JAMI, Japan Society for Healthcare Administration and Medical Information System Development Center.

\section{Annual Conferences}

In June 2015, 18th Spring Symposium was held in Sendai. Prof. Jun Nakaya was the president of the conference. 1100 participants gathered and its theme was "Compass: Positioning of Medical Informatics - Practice, Research, and Education". In November 2015, 35th National Conference was held in Okinawa. Prof. Ryuichi Yamamoto was the president of the conference. 2000 participants gathered and its theme was "Use of Health Information and Protection of Privacy - run after two hares, and you will catch both". In July 2015, 16th Nursing Informatics Conference was held in Matsue. Ms. Haruko Iwata was the president. Total of 18 local charter conferences and special interest meetings were held in 2015.

\section{Translational Biomedical Informatics Conference}

Analysis of genomic information and translation of findings in basic research into clinical medicine are increasing. Genomic data already exists in hospital information systems, and biomedical data and lifestyle data are a part of healthcare information in clinical research to improve individual health and population health, and for preventive healthcare. JAMI has hosted the Translational Biomedical Conference in November 2015 Tokyo, where distinguished researchers from abroad gathered on this special occa- 
sion, and we had 250 participants. JAMI is keen to identify and resolve issues with the discipline of biomedical informatics in terms of sociology and ethics as well as clinical medicine and healthcare information technology, which is one of our major action items. www.jami.jp/english/document/ JAMI_Responsibilities_Actions_2014.pdf

\section{JAMI Certification of Healthcare Informa- tion Technologist}

JAMI Healthcare Information Technologist (Healthcare IT) Certification program was inaugurated in 2003 to cultivate human resources in healthcare information technology and to support career development of health information professionals. The certification is intended for healthcare professionals, software engineers, managers, vendors, and others involved in Healthcare Informatics. The required knowledge and skill sets are made up of a) Information Technology, b) Health Care and c) Health Information Systems. Abilities of "Communication, Collaboration, and Coordination" are considered essential to a qualified Healthcare IT. In 2015, the 13th annual examination was given in 11 cities around the country, and 1,697 people out of 4,748 passed the examination. As of January 2016, a total of 17,311 people were certified as Healthcare ITs. The Senior Healthcare IT certification examination started in 2007, and the 9th examination was given in 2015. As of January 2015, 309 Senior Healthcare ITs were certified.

http://jami.jp/hcit/HCIT_SITES/doc/ pdf/090522HealthITOverview.pdf

\section{New Zealand}

Inga Hunter, Healthcare Informatics New Zealand (HINZ)

HINZ had another very successful and transformative year. Our annual conference in Christchurch achieved a record 816 delegates, $33 \%$ above the previous year. The conference included a one day 'Nursing Informatics Conference' (NZNIC) which sold out with 130 delegates. For the first time we recorded webcasts of every session across four concurrent streams and offered 'virtual conference registrations' which got an excellent uptake. The Minister of Health confirmed the importance of health IT by emphasizing its key role in the Government's newly launched health strategy and he asked to be invited back to speak at our conference in 2016.

Other initiatives completed this year included the launch of a new website with expanded functionality, the delivery of two hour educational primers nationwide (free introductory workshops on health IT for clinicians), two health hackathons and a sell out one day seminar.

We are currently working on plans to achieve another first with our 2016 conference. We are partnering HiNZ-16 and NZNIC-16 with two international conferences (GT-16 and SFT-16) and will deliver four confer-ences in one dynamic week in Auckland in November 2016. Delegates will register once and be able to at-tend any session across the four conferences.

\section{Philippines}

Erwin Brian Tan, Philippine Medical Informatics Society (PMIS)

The recent years have been very exciting times for the Philippine Medical Informatics Society (PMIS) as members from different fields and professions joined together to increase the awareness of the country about the role of Medical Informatics, the benefits of Telehealth in our everyday health, and the assistance of the Internet in improving the field of Medicine.

Now on its 20th year, since it was founded in 1996, the PMIS presently has more than 1,000 members on its roster and continues to play a central role in the expansion of health informatics in the country by holding various symposia and partnering with different health and IT groups that promote public awareness of technology in healthcare.

The society and along with partners from the private and public sector, with several local and international Internet stakeholder organizations, held a convention called Internet20 $\mathrm{PH}$ discussing the past, present and future of Internet in the Philippines as a celebration of the landmark event in Philippine Internet History.

March 29, 2014 marked the 20th anniversary of Internet in the Philippines. PHNET (formerly called Philnet) is a collaborative project of the Department of Science and Technology (DOST) and several academic institutions, which connected officially to the Internet on the same date in 1994. The Phil- net project began in July 1993 with a limited electronic facility linking DOST, Ateneo de Manila University (ADMU), De La Salle University and U.P. Diliman. A year later through a connection with Victoria University of Technology (VUT) in Australia, through the institutional ties with ADMU, became the gateway to the Internet while ADMU acted as the local relay hub for the Philippines.

Internet20PH: Connecting Filipinos to the World was a week-long event commencing on the 27th of March to 4th of April 2014 at Crowne Plaza Hotel, Quezon City, Philippines. A series of workshops, conferences, technical trainings and other relevant activities were conducted to highlight the successful establishment and continuous evolution of the Internet technology in the Philippines.

In relation to this, it is of note that the government has also passed laws to protect local ,netizens' against cybercrime, among the legislation that have been passed are the e-commerce law and the controversial cybercrime prevention act, which is currently under review.

Among the co-organizers of the event and Internet stakeholders present were the Philippine Chapter of the Internet Society (ISOC-PH), the Asia Pacific Network Information Centre (APNIC), Trans-Eurasia Information Network (TEIN) and the U.P. Institute of Environmental Science and Meteorology (IESM).

And finally, recognizing the strong influence of social networks, PMIS established a presence in Facebook (www.facebook. com/groups/philmedinfo) and encouraged knowledge exchange and resource sharing within this environment. The PMIS Facebook group discusses topics ranging from electronic medical records to privacy to knowledge management. It has also become an important repository for eHealth blogs of students from the University of the Philippines Manila Master of Science in Health Informatics.

The Philippine Medical Informatics Society continues to push the boundaries of health education and information exchange with its participation in the different academic institutions of the country. It stays firm on its stated purpose and mission, which is to promote and develop the application of information technology in the field of Medicine and Public Health, in 
order to improve the quality of healthcare of the Filipino people.

\section{South Korea \\ In Young Choi, Korean Society of Medical Informatics (KOSMI)}

The Korean Society of Medical Informatics (KOSMI) celebrated its 25th anniversary two years ago. As of December 31, 2014, KOSMI has more than 6000 different types of members consisting of 223 life time members, 130 full members, 43 student members, $5669 \mathrm{Web}$ members and 12 institute members.

KOSMI plays a very important role in the field of biomedical informatics in Korea by providing opportunities for sharing and exchanging information and knowledge in the field. Main activities of the KOSMI include hosting regular biannual academic conferences, seminars on different topics, and publishing the Health Informatics Research (HIR), an official journal of KOSMI four times per year.

The Spring conference was held at College of Nursing, Seoul National University in Seoul from August 10 to August 11. The theme of the conference was "Creative Fusion for Better Health" and 270 members participated in the conference. There were 3 tutorials, 8 symposiums, 14 paper presentations and 19 poster presentations. Three papers and one poster were awarded and recognized as the best papers and poster respectively at the conference.

The Fall/Autumn conference was held at Konyang in Daejeon from November 26 to November 27. The theme of the conference was "New Vision and New Education for Medical Informatics" and 189 members participated in the conference. There were 2 tutorials, 14 symposiums, 14 paper presentations and 24 poster presentations. Three papers and one poster were awarded and recognized as the best paper and poster at the conference.

KOSMI published the 21st volume of the HIR in 2015. The KOSMI currently publishes all of the four issues in English. In general each issue publishes 1-6 review articles, 4-7 original research articles, 1-3 case reports and a book review. The Journal was accredited by the Korea Research Foundation in 2006 and registered as one of prestigious academic journals in Korea.
Currently KOSMI officials and editorin-chief are working hard to promote the Journal as one of the SCI journals.

KOSMI welcomes all to APAMI 2016 to be held from November 2nd to 5th 2016 in Seoul, Korea.

\section{Sri Lanka}

Dr Vajira Dissanayake, Heath Informatics Society of Sri Lanka (HISSL)

As of November 30, 2014, HISSL had 275 members. The membership consists of medical, health and IT professionals, academics and students who are interested in Medical and Health Care Informatics. HISSL maintains close relationship with the Ministry of Health providing assistance in policy formulation and implementation in Sri Lanka's eHealth landscape as its main technical partner. HISSL supported the Ministry of Health to finalize the Health Information Policy of Sri Lanka and the National eHealth Guidelines and Standards to foster a standard based interoperability framework to harness the full potential of eHealth for the future. This year the annual conference of HISSL, eHealth Sri Lanka, was rebranded as eHealth Asia with the view to showcasing some of the eHealth Initiatives in Sri Lanka regionally. Towards this end, it was organized jointly with the Asia eHealth Information Network (AeHIN), the World Health Organisation, the Ministry of Health Sri Lanka, and the Information and Communication Technology Agency of Sri Lanka (ICTA). The conference held on 13 and 14 October 2015 was webcast live view AeHINs webex platform. It was attended by over 300 delegates and many more online. Participation of the Minister of Health, Minister of Telecommunication and Digital Infrastructure, and the Minister of Higher Education of the newly elected government of Sri Lanka at the inauguration signified the emphasis placed on eHealth as a strategy to improve the health care system by the new government. The archive of the conference can be accessed at http://ehealthasia.org. Another initiative to share our expertise regionally is the Sri Lanka eHealth Hour which is webcast live on the AeHINs webex platform. The archive of this can be accessed at www.hissl..lk/index. php/sl-ehealth-hour. This year too HISSL continued to support the Postgraduate Institute of Medicine (PGIM), University of Colombo, Sri Lanka to conduct the MSc in Biomedical
Informatics Course. In addition it supported the PGIM to design the new MD course in Health Informatics. Extending its expertise to strengthen the regional health Informatics community, HISSL, signed a MOU with the School of Computing, Kathmandu University, Nepal to help them launch a Masters in Health Informatics in Nepal. HISSL was also represented in several regional and international conferences to promote fellowship, exchange of ideas and best practices. These included the Plenary and Post Conference Symposia at the Global Telehealth 2015 Conference in Toronto, Canada in June 2015 and the Conference on Measurement and Accountability for Universal Health Coverage in the Asia Pacific and the AeHIN 4th General Meeting in Bali, Indonesia in October 2015. The HISSL's leadership role in health care IT in Sri Lanka was further highlighted when the leading Sunday News paper in Sri Lanka, Sunday Times, invited the President of HISSL to write a monthly column in it Business Section. This column has been highly popular and attracted the attention of the local and global readership.

\section{Taiwan}

Jack Li, Taiwan Association for Medical Informatics (TAMI)

TAMI has successfully hosted the annual JCMIT 2015 with keynote speakers including HL7 CEO Dr. Charles Jaffe, Michio Kimura from Hamamatsu University and Prof. Thomas Wetter from Heidelberg University in June with about 400 participants.

The DOHW (Department of Health and Welfare) started to host an online EHR (My Health Bank) for all the citizens in Taiwan to access their own diagnoses, medications, lab results and dental health information. More than 150,000 started to access it using their own Health Smart Card as the authentication token. A Hackathon-like event was also hosted to encourage Apps development to utilize this personal EHR online.

A 5-year EHR certification effort concluded in 2015 and 405 hospitals (81\%) passed the certification.

Compiled by Klaus Veil, APAMI Secretary Secretary@APAMI.org

\section{APAMI Web Site}

http://www.apami.org 


\section{Helina}

\section{Activities of the Pan African Health Informatics Association}

\section{Next Helina Conference}

The next HELINA Conference will be hosted by the Burundi Health Informatics Association-BHIA- from 23 to 26 April 2017 in Bujumbura, Burundi. BHIA will involve the newly created Rwanda Health Informatics Association in organizing this conference. The proposed date was based on the proposition of the IMIA-Board to integrate its 2017 meeting in the HELINA Conference. HELINA will be proud to receive the IMIABoard. This is an opportunity to attract more international participants.

The suggested title of the conference is "Integrated Health Information Management Resources for Global Healthcare Strategies". The following topics are proposed as the main themes for the conference:

- National and Regional eHealth Strategies and Policies

- Health Information Systems Interoperability

- Human Information Systems Interoperability

- Human Capacity building for eHealth

- Sustainable systems implementations

The focus of the conference will be on the development and implementation of integrated eHealth plans and policies that build bridges between the existing information management silos and that will propose pathways to fill high priority gaps: infrastructure, eHealth enabled human resources, international standards application, legal and ethical frameworks, sustainable funding mechanisms, and robust and down-to-earth ICT solutions. Special attention will be paid to the new WHO/UN Sustainable Development Goals (SDG) and more specifically to goal 9, target 9c "Significantly increase access to information and communication technology and strive to provide universal and affordable access to the Internet in least developed countries by 2020". In addition, the positive experience from HELINA 2015 in Accra will be capitalized by organizing a number of practical workshops that are freely available to all HELINA attendees. The following meetings will/can be scheduled in the margin of the conference:
- IMIA Board meeting

- HELINA GA meeting

- HELINA WG meetings (education, interoperability, Data Mining and Big Data Analytics, and nursing informatics)

Journal of Health Informatics in Africa (JHIA)

The new editor-in-chief of JHIA is Prof. Dalenca Pottas, Director of the School of Information and Communication Technology, Nelson Mandela Metropolitan University, South Africa. Nicky Mostert-Phipps and Frank Verbeke, the Scientific Programme Co-Chairs of HELINA 2014, have joined the editorial team.

We wish to express our deepest gratitude and thanks to Prof. Mikko Korpela for his uninterrupted contribution to the development of health and biomedical informatics in Africa. Mikko accepted without hesitation the invitation to become the first editor-in-chief of an idea called "Journal of Health Informatics in Africa" (JHIA). He brought JHIA from an idea to the threshold of becoming an indexed, acknowledged, and stable international scientific journal for the Health and Biomedical Informatics community in Africa.

\section{HELINA's Working Group: Data Mining and} Big Data Analytics

\section{A - Background}

The Data Mining and Big Data Analytics group was launched at the 9th HELINA conference in Ghana and confirmed as an official Working Group under the Leadership of Dr. Georges Nguefack-Tsague, Senior Lecturer of Biostatistics and Health Informatics at the Department of Public Health of the Faculty of Medicine and Biomedical Sciences, University of Yaounde 1, Cameroon, at the HELINA General Assembly meeting on Sunday 8th March 2015.

Objectives:

1. Promoting data mining and big data analytics in Africa;

2. Promoting the secondary use of big data;

3. Strengthening stakeholders in health informatics in Africa with practical (software based) skills in data mining and big data analytics.

The format of the Working Group is through Work Sets, consisting of members, who have volunteered to give their time and expertise in specific planned activities on behalf of HELINA.
Each Work Set has a coordinator, who is responsible for the Work Set. The role of the coordinator is to recruit and manage the activities and projects within the Work Sets and prepare progress reports for the Chair to present to the HELINA Board and HELINA General Assembly when requested.

\section{B - Activities for 2015/2016}

1) Creation of web page for the WGs and Forum

A platform for web discussions has been created for the WGs in LinkedIn with the following link: https://www.linkedin.com/ groups/8481534

This platform currently has 30 members.

2) Activities of the Work Set 1: Analyzing Demographics and Health Surveys (DHS) data in various African countries. The Demographic and Health Surveys (DHS) Program has collected accurate and representative data on population, health, HIV, and nutrition throughout many African countries. This tremendous amount of information is freely available to the public and is underutilized. The objective of this Work Set is to promote the use of data mining techniques to analyze DHS data in various Africans countries.

Dr. Georges Nguefack-Tsague, Coordinator of the Work Set, attended a Regional DHS/MIS Malaria Analysis Workshop held on 7-15 March, 2016 in Dakar-Saly (Senegal). He has benefitted through financial support from USAID.

3) Within the framework of the objective of promoting data mining and big data analytics in Africa, Dr. Georges Nguefack-Tsague also attended a workshop on analyzing data from HIV programs for female sex workers held on 21-25 September, 2015 in Dakar-Somone (Senegal), with joint financial support of UNAIDS, World Bank, and USAID.

4) Recruitment of new members of the WG from throughout Africa:

Seventeen individuals from Benin (3), Burkina-Faso (2), Cameroon (1), Madagascar (2), Mali (3), Senegal (3), and Togo (3), most of them interested in the Work Set 1 on DHS, have joined the WG as new members. 


\section{C - Perspectives}

1. As can be noticed, only one Work Set was functional. Thus efforts should be made to make other Work Set functional;

2. The only web activity is via LinkedIn, there is the need to effectively create a web page for the WG;

Other planned activities should be implemented in the coming year; these include: a) Software, references, and notes on data mining and Big data analytics; b) Locating major big data base on health in Africa, and c) Situational analysis of education on data mining and big data analytics in Africa.

\section{Helina Education WG}

\section{Support of Young Authors and the HELINA Journal}

HELINA education working group was launched as an official Working Group under the leadership of Professor Graham Wright at the meeting of the HELINA Board on March 2015. The main aim of the working group is to foster the objectives and policies of HELINA by providing a platform for the development of initiatives to support the membership of HELINA in relationship to Health Informatics Education, Training, and Research.

The working group identified seven worksets for its initial activities, which will be undertaken by members, who have volunteered to give their time and expertise in specific planned activities on behalf of HELINA. Among the worksets is the PAFENA initiative (Pre-submission Advice and Feedback to Neophyte Authors), which aims to provide a pre-submission review system of papers to increase the paper acceptance rate by offering advice and feedback to authors from Africa. The support is mainly feedback on the methodology and language. The initiative also aims to continuously mentor, support, and advise junior Health Informaticians, who are planning to publish a paper in a HELINA - IMIA event or Journal.

Currently, the WG is establishing a network of volunteer authors within each HELINA country in collaboration with the country representative to prepare a database of volunteers in different specialties. In the future, the plan is to establish a student edi- torial board in the Journal of Health Informatics in Africa so that $\mathrm{PhD}$ and postdoctoral fellows can support the peer review process as well as learn from the feedback of editorial members on their reviews.

If you have experience in research and you have published at least one article in a peer reviewed journal, you are welcome to be a member of this initiative so that you can help others by reviewing papers for common methodological and grammatical mistakes.

\section{The Francophone interest group of the WG Education of HELINA}

This special group of the WG Education is coordinated by Dr. Frank Verbeke, Université libre de Bruxelles and University of Rwanda. It focuses on the development, implementation, and promotion of francophone training \& e-Health education programs in sub-Saharan Africa. Currently several initiatives are under development: 1. The creation of francophone MSc HI courses for West- and Central Africa. Course materials and teaching staff will be shared by both masters programs, with some customization to local and regional realities. The group is studying the possibilities to host the West African program at the Université Cheikh Anta Diop in Dakar and the Central African program at the Université Lumière in Burundi. Funding opportunities are explored mainly with development cooperation from francophone (bilateral) donors. The ICT4Development group from the Vrije Universiteit Brussel is taking the lead in the academic coordination of the initiative (submission of the program content for Belgian accreditation) in collaboration with the University of Geneva. 2. The implementation of a francophone „Health Information System" course (Formation sur les Systèmes d'Information Sanitaire, at least 10 ECTS) with strong focus on sub-Saharan Africa by a consortium of Université Libre de Bruxelles (ULB), Vrije Universiteit Brussel (VUB), University of Oslo, Measure \& Evaluation, AEDES. The course will be organized yearly in a francophone country, probably the first year in Brussels (Ecole de Santé Publique ULB) or Bamako (Université du Mali).

3. The development of a library of free $\&$ open French e-learning materials in
Applied Health Informatics (methods \& applications) with financial support from the ICT4D Foundation.

\section{Website Progress}

A website for the HELINA Education Working Group has been set up at http:// wg-education.helina-online.org/. It currently has basic information on the WG, its aims and members, and on planned activities. Workset leaders will add further information on activity, and update aims and objectives.

\section{Other Communication and Online Groups}

A LinkedIn Group has been set up https:// www.linkedin.com/groups/8274552 which now has 47 members.

An experimental YouTube repository of Keynote and Inaugural Addresses is being tested at https://www.youtube.com/ playlist?list=PLw9K8MaSa0Q9ODGjzpLvKOFs1GAPapV2d which is intended to be the prime repository for video materials.

\section{Southern Africa Nursing Informatics Special Interest Group (SIG)}

The HELINA status of the group will be confirmed at the next HELINA General Assembly. The group has a LinkedIn site https://www.linkedin.com/groups/8369314 for communication and is represented on the IMIA-NI General Assembly by Prof G Wright and a corresponding member.

The group has been awarded the honour of organising the IMIA-NI 2018 congress in South Africa and has begun working on the business plan with the Conference Company. It is proposed that the venue will be the Century Conference Centre in Cape Town during August or September 2018.

The conference's proposed title is Transformation through Implementation Science: using information to improve patient care.

Implementation science is the study of methods to promote the integration of research findings and evidence into healthcare policy and practice. It seeks to understand the behaviour of healthcare professionals and other stakeholders as a key variable in the sustainable uptake, adoption, and implementation of evidence-based interventions.

The format will be different from the normal congresses and will be based on 
four Colloquiums, each of which consists of a 90 minute Research Based presentation, followed by 30 minutes of questions. In addition there will be a paper stream for expert and neophyte presenters; the latter will be supported by the HELINA Education WG to prepare papers.

The other major difference will be an Exhibitors Hall which will host Poster Sessions, Demonstrations, Tutorials, and Case Study Presentations throughout the event.

A major objective of the organisers is to reduce the cost to participants, the Exhibition

\section{IMIA-LAC}

\section{Health Informatics Association for Latin-America and Caribbean}

\section{Membership of IMIA-LAC}

To date, 12 medical informatics societies from Argentina (AAIM, Hospital Italiano), Bolivia (SOBOTIM), Brazil (SBISS), Colombia (ACIESA), Costa Rica (MoH), Chile (ACHISA), Cuba (MoH/SCIM), El Salvador (IMHS), Mexico (AMIM), Peru (SOPTIS), Puerto Rico (SHILAC) and Uruguay (SUIS) constitute the Federation of Health Informatics for Latin America and Caribbean.

\section{IMIA-LAC GA Meeting}

The last IMIA LAC GA Meeting was held on 3rd July, 2015 via a Skype conference call. The IMIA LAC 2017 bid was carried out smoothly among SCIM, ACHISA, SOBOTIM, and SHILAC, and Cuba (SCIM) won the bid to host the IMIA LAC conference in Varadero, Cuba in 2017.

The current IMIA-LAC Board is comprised of: President: Dr. Amado Espinosa (AMIM) President-elect: Dr. Claudio Giulliano (SBISS) Secretary: Dr. Erika Caballero (ACHISA) Treasurer: Dr. Carol Hullin (ACHISA)

\section{Members' Activities 2015-2016}

\section{Argentina}

About 250 people from the field of health and technology attended the X Informatics Symposium held in Hospital Italiano de Buenos Aires during the 9, 10 and 11 November and followed the events through remote connections. On average, each virtual classroom had about 70 followers connected
Registration fee should be either a nominal amount (150 Rand) or FREE (the exhibitors can invite attendees as their guests.)

The Main Congress will have an entrance fee of 4000 Rand for IMIA members and 1000 Rand for HELINA and Southern Africa Nursing Informatics Members.

Prof $G$ Wright is the congress chair, with Dr Helen Betts chairing the LOC and Dr Peter Murray chairing the SPC.

The group will have an exhibition stand at IMIA-NI 2016 and present a progress report to the IMIA-NI board and GA.

\section{Acknowledgements}

I would like to thank Prof Graham Wright and Dr. Georges Nguefack-Tsague, and Frances da-Costa Vroom for their contribution to this report.

\section{Regional Editor}

Ghislain B. Kouematchoua Tchuitcheu, PhD IMIA Vice President for HELINA

E-mail: kouematchoua@helina-online.org ghislain.k@koegni-ehealth.org

www.helina-online.org to some activities and reached up to 90 participants logging in, all of whom had the opportunity to pose questions to the speakers.

The record number of 500 participants exceeded the average 300 participants in previous editions. The large number of participants evidenced the sustained growth of the conference, which definitely established itself as a must attend event for academic updates in eHealth in Latin America.

As in previous years, with the contributions by the University Institute of the Hospital Italiano and the Standards Association Health Level Seven, and with Dell and SemperTI-Red Hat companies as sponsors, a program of panels and plenary sessions offered workshops, simultaneous training sessions, vendor displays and even a connecthathon: professionals in charge of the Department of Health and Biomedical Informatics simultaneously developed new activities and initiatives.

After the meeting Dr. Daniel Luna thanked the organizing committee of the conference, made up of the professional team of the Department of Health Informatics, experts from government, hospitals, companies, and associations, who shared their experiences, and international experts who joined this confernce: James Cimino (United States), Isabella Scandurra (Sweden), Isabel de Jesus Simao (Germany), Luiz Evangelisti (Brazil) and always welcomed company: Selene Indarte, Jorge Forcella, Jorge Abin (Uruguay).

\section{Cuba}

XI International Congress of Health Informatics 2016

PRESIDENT: Lic. Alfredo Rodríguez Díaz. Informatics and Communications Director. Ministry of Public Health
VICE-PRESIDENT. Dra. Esperanza O'Farrill Mons. President of the Cuban Society of Medical Informatics.

\section{GOAL AND SCOPE}

Informatics for Health 2016 aims and objective were to conduct fundamental research, promote, analyze and learn about the progress of information technology, telecommunications, electronics, medical equipment, and automation in Cuba's health care and in the world. The congress will have space for scientific and academic exchanges between professionals, scientists, engineers, businessmen, government representatives, International Organizations, and the general public interested in research.

\section{TOPICS}

eHealth and clinical practice:

Informatics for Primary Health Care. Informatics in isolated communities. Open Systems for Health. Quality guarantee. Energy saving Collaborative work and learning network: E-learning in health. Knowledge and pedagogical or technological practices in health education networks. Data mining and pattern recognition. Health virtual libraries. Modeling, simulation, and artificial intelligence. Statistical Processing. Content Management Systems. Artificial intelligence applications in health.

Networking for nursing development:

Computers in Care Management. Computer applications in nursing processes. Networking for the development of nursing. ICT in nursing educational processes. The computer education and knowledge management in nursing. Medical technologies and telemedicine: Telematics. Database management for health. Internet as a tool for health. Tele- medicine. mHealth 
Informatics, society and health: Rules and regulations on the use of ICT in Health. Informatics for public health. Information advanced integrated systems in health. Informatics and STD/HIV/AIDS. Health surveillance.

New technologies of information and clinical practices: Clinical research. Image processing and medical signal. Instruments and systems for monitoring and diagnosis. Neuro- informatics. Bio- informatics

\section{COLLABORATORS}

- Pan American Health Organization

- Cuban Society of Medical Informatics

- National Center of Information of Medical Science

- Cuban Society of Nursing

- Pan American Federation of Nursing Professionals

- Red ENFAMERICA

The conference offered a unique opportunity to meet government and academic authorities responsible to develop MI locally which was especially interesting now that the socio economic change is taking place.

\section{Mexico}

Tele Health Conference of the Americas 2016 (July 20-23th) with the participation of PAHO -WHO, Ministry of Health from Peru, Colombia, Argentina, Uruguay, Panama \& Mexico. Topics: Using mobile phones for Telehealth, remote diagnostics. Experiences, Telehealth program evaluation, Communication networks in Telehealth, Patients and their relationship with the Telehealth, Innovation support systems for remote diagnostics, Infrastructure developments, Telehealth training programs, Normativity and regulation in Telehealth (research). The conference attracted over 300 attendees.

\section{Puerto Rico}

The Symposium of Health Informatics in Latin America and the Caribbean (SHILAC), and the MIT "Hacking Medicine" hackathon took place in Puerto Rico on November 20-22, 2015.

The objectives were:

1 To identify common issues that may be addressed with informatics including important public health issues requiring collaborative solutions including a wide array of disciplines and decision makers
2 To showcase the health informatics research and industry in Latin America and the Caribbean and describe the challenges and lessons learned

3 To brainstorm how to bridge the gaps among disciplines to develop more collaborative and diverse research and form industry teams for more efficient solutions to health informatics issues in developing countries

4 To solve healthcare problems and implement computational and informatics solutions for developing and developed countries using mobile technology

The conference attracted participants from 10 different countries, AMIA members, local and regional institutions, multidisciplinary students, industry and public authorities.

The meeting helped to create better awareness about the opportunities to collaborate at the regional level among academia, industry, and authorities through a high level of the scientific program for posters and presentations.

\section{Nursing Informatics Group}

During the participation at the conference in La Habana, a meeting with the representatives of the Cuban Society of Nursing, the Pan American Federation of Nursing Professionals, and the Red ENFAMERICA took place. Different initiatives for future collaboration and support from IMIA LAC to their groups were discussed. The next meeting will take place in Mexico, during the Nursing Informatics group's next conference.

- Virtual Meetings

January - Strategic planning for the biennium 2016-2017

February - Coordination meeting in Mexico and Symposium Nursing Network Informatica.

- Contribution and sustainability of visualization of International Nursing Network websites Observatory PAHO / WHO (http://www.observatoriorh.org/?q=redes-internacionales-de-enfermeria ) and Blog for collaborative work (http://blogs. sld.cu/vialart/ )

- Projects: Proposal for a joint international research project on the Zika virus.

- Teleconferences: Virtual libraries health or nursing. April. Brazil
Implications of the concept of knowledge in computer programming: philosophy of care. April, 21st, Spain

Use of Information and Communication Technologies in health, as a strategy to achieve universal health coverage in the nursing process. May 6th, Cuba

Ontological Bases in computer science or nursing: the axioms of care. May 12th, Spain Formal representation of health concept: basis for the study of comprehensive care. June 9th, Spain.

ICT and Education in Nursing. June 16th, Argentina

Tecnoantropology in health informatics. July 8th, Chile

Tool for normalization of nurses ratings: coded language to natural language. July 14th, Spain

Importance of Nursing in educational institutions and their relationship with Nursing Informatics. August 18th, Peru. Experience of Cuban nursing care for people living with HIV / AIDS through mHealth. September 15th, Cuba Representation of standardized nursing languages: the concept of process the concept of care cycle. October 13th, Spain Experience of Nursing Informatics in Uruguay. October 20th, Uruguay

Decision algorithm in the field of care: an approach in vaccinating people. November 10th, Spain

Sequencing of nursing knowledge or in the virtual environment: an experience from the anatomic-physiology. December 15th, Spain

\section{PAHO - WHO}

In order to provide a better level of institutional exposure for the local societies, a meeting was arranged with the representative from PAHO (David Novillo, Regional Advisor, eHealth and Knowledge Management), during the conference in Mexico. Important issues were discussed like the collaboration opportunities with the "Telehealth Network of the Americas" from the Organization of American States, e-Health International Telecommunication Union Group, e-LAC (UN-CEPAL), and the Information and Communication Technologies (ICTs) in Health Systems from the OECD. In conclusion, participants agreed on preparing a proposal based on the terms of the MOU 
between IMIA and WHO, observing the terms and conditions of PAHO to collaborate, and work on a document which can integrate elements from the above mentioned initiatives to integrate IMIA LAC properly.

\section{Institutional Relationships}

We're preparing a proposal for a collaborative relationship between AMIA, EFMI, and

\section{MEAHI}

\section{Middle East Association for Health Informatics}

The MEAHI first Special Topic Conference (MEAHI STC 2015), which was the fifth MEAHI event since its inception in 2002, was held from the 15th to 17th December 2015 at the Health Sciences Center, Kuwait University, Kuwait. The theme of the MEAHI STC 2015 was "Standards and Interoperability in Healthcare Informatic" Contributions were very international with keynote talks and plenary speeches from Australia, Canada, Denmark, Egypt, India, Iran, Japan, Korea, Kuwait, Singapore, Taiwan, UK, and the USA. The conference speakers were chosen from well-known academia, regional governments, WHO-EMRO, industry, and NGOs to create a logical balance in addressing a variety of topics in respect to the conference theme from policy to practice. The KIMS (Kuwait Institute for Medical Specialization) approved seventeen CME (Continuous Medical Education) credits for this conference. The conference was co-chaired by Dr. Ramin Moghaddam and Mr. Hamza Alshawaf. The official language of the conference was English. A copy of the conference program can be found online at http://www.meahi. org/\#!conference-program/c1tl3.

- Pre-conference day :

- The IEEE 11073 Standards for Personal Health Devices (UK)

- Visualizing Phenome-wide Association Profiles in Taiwan (Taiwan)

- Disease Association Maps: A Novel Tool for Disease Associations Prediction (Taiwan)

- The 2-day conference :

- WHO/EMRO's work on eHealth: Pro-
IMIA LAC, starting with the working groups, and looking for an institutional exchange of experiences and support. We will try to adopt the model of the industry and invite Spain \& Portugal to become members of the region.

A special committee to prepare a proposal for the collaboration with AMIA has been already integrated, to have an active channel of regional projects.
Regional Editor

Dr. Amado Espinosa

IMIA-LAC President

IMIA-LAC website

www.imialac.org gress, Opportunities, and Challenges (Egypt)

- Healthcare Informatics standards: A quick Journey through the Islands (Iran)

- Use of standardized terminology and clinical detailed models to improve interoperability of nursing data (Korea)

- National Health Information system Situation Analysis and Assessment (Kuwait)

- HIE's - Building on and Benefiting a Federated Health Care Delivery System (Canada)

- E-Health Interoperability and Standards: Guidelines put into practice at All India Institute of Medical Sciences (India)

- Electronic Patient Records (EPR) standards (Kuwait)

- Innovative Ambulatory Care services and integrated e-Health solutions (USA)

- Internet of Things (IoT) in Healthcare Informatics (Taiwan)

- Future Trends in Picture Archiving and Communication System (PACS) - (UK)

- Health 3.0 opportunities, challenges, and impacts on healthcare settings (USA)

- Model EHR Format for Children(USA)

- Data as a Healthcare Corporate Asset (Singapore)

- Taking mHealth Interoperable - Issues and Advances (Canada)

- Standards for International Travelers' Personal Health Records (Taiwan)

- Bio-patch: Wireless telemonitoring of vitals (Taiwan)

- SNOMED CT Introduction : Healthcare Terminologies (Denmark)

- A National Referenced Health Semantic Model (Iran)

- A rapid tour on how HL7 standard brings Interoperability in healthcare Informatics (Singapore)
- openEHR: an open platform for clinical data (Australia, UK)

- Reinforcement and localization of the openEHR specifications and ISO 13606 standards (Japan)

- Iranian Electronic Health Record for Integrated Care (Iran)

- A set of Recommendations and Action Plan for Harmonization and Adoption of Healthcare Informatics Standards from Policy to Practice levels in the Middle East Region (Iran)

As a common practice, the WHO regional office (EMRO) has been engaged in all MEAHI events since its beginning. Since the conference theme was in line with the WHO's resolution on eHealth standardization and interoperability (WHA66.24 on 27 May 2013), the WHO sponsored two internationally recognized keynote speakers from Canada and the UK and assigned an official representative, Eng. Hani Farouk, who gave a keynote talk and attended in all sessions.

Since early 2016, we have focused on recommendations for MEAHI STC 2015 with regard to harmonization and adoption of Healthcare Informatics Standards in the region. With respect to this initiative, a taskforce was formed to involve different regional and international stakeholders. We expect for some tangible results this year.

As part of our regular activities, we are working on next MEAHI STC (MEAHI second Special Topic Conference), which will be the sixth MEAHI event.

\section{Regional Editor}

Dr Ramin Moghaddam, MEAHI Founding President \& MEAHI Supreme Council Chair Dr_Moghaddam@Meahi.org 


\section{North American Medical Informatics (NAMI)}

\section{Health Informatics in Canada}

COACH: Canada's Health Informatics Association

COACH: Canada's Health Informatics Association is the voice of health informatics (HI) in Canada, promoting the adoption, practice and professionalism of HI. COACH represents a diverse community of accomplished, influential professionals who work passionately to make a difference in advancing healthcare through IT. HI is the intersection of clinical, IM/IT and management practices to achieve better health. Now in its 41 st year as the national association for $\mathrm{HI}, \mathrm{COACH}$ continues to develop significant, exciting initiatives to provide leadership in the evolution of $\mathrm{HI}$ as a profession in Canada and fully realize the vision of taking $\mathrm{HI}$ mainstream.

As the health system undergoes major, foundational change, $\mathrm{COACH}$ remains steadfast in this commitment, with the goal of promoting better information for better health outcomes. $\mathrm{COACH}$ is focused on bringing together all segments of the digital health ecosystem, including traditional players and new entrants. Enhancing the quality, speed and impact of knowledge exchange, development of professional resources and collaboration opportunities across sectors and Canada is the goal.

\section{Conferences and Events}

The annual e-Health Conference, presented in conjunction with Canada Health Infoway and the Canadian Institute for Health Information, is one of COACH's most successful progams. The largest Canadian education, trade show and networking event for IM, IT, clinicians, telehealth and other healthcare professionals, e-Health 2015 attracted approximately 1,700. e-Health 2016 will take place in Vancouver, BC June 5 - 8. The conference covers the breadth of e-Health: information, solutions, implementations, technology, innovations, impact and more and provides more than 100 hours of education, including the popular e-Health Rants and hackathon.
$\mathrm{COACH}$ also offers a valued regional conference program that supports education and networking during the year for major regions. Other events include weekly Webinar Wednesdays, focusing on best practice, research and emerging issues in the HI field. In addition, $\mathrm{COACH}$ and ITAC Health co-host the Canadian Health Informatics Awards (CHIA), which are presented at the annual CHIA Gala during the e-Health Conference.

\section{Professionalism}

COACH's Health Informatics Professionalism (HIP $\left.{ }^{\circledR}\right)$ Program is rooted in the association's deep commitment to promoting the adoption, practice and professionalism of health informatics. This is particularly important in light of new and changing roles in the field, as reflected in research such as *COACH's Canadian Telehealth Report, published most recently in 2015. The only source of national jurisdiction-specific telehealth data in Canada, the report provides a "snapshot in time" of the state of telehealth and its impact on virtual care roles and other aspects of the profession.

In addition, the need for 6,200 to 12,200 more professionals, including $70 \%$ in IT and health information management roles (HIM), by 2019, is documented in the *Health Informatics and HIM Human Resources Outlook Report. The following resources are key components of the HIP ${ }^{\circledR}$ Program.

- HIP ${ }^{\circledR}$ Core Competencies 3.0: An eBook PDF outlining the 50 core competencies knowledge, skills and capabilities - that HI professionals need to perform effectively in a wide range of practice settings. The $H I P \circledR$ Competency Framework, the foundation of the professionalism program, is another key element.

- HIP® Career Matrix: The first illustration of the breadth and depth of career possibilities in Canadian HI, featuring 65 jobs.

- HIP® Role Profiles: Provides high-level outlines of the main responsibilities, key competencies, etc., for the job titles on the Career Matrix.

- HIP® Career Navigator: A web tool integrating the Core Competencies, Role Profiles and Career Matrix, available only to $\mathrm{COACH}$ members.
- CPHIMS-CA: The only professional HI credential in Canada. [Available through a partnership with the Healthcare Information and Management Systems Society (HIMSS)]

- Health Informatics Education in Canada: Landscape of an Emerging Academic Discipline Report: Examines Canadian HI programs, from diploma through PhD levels.

\section{Membership Forums}

\section{CHIEF: Canada's Health Informatics Executive Forum}

CHIEF provides an interactive, trusted environment enabling senior executives and industry leaders to collaborate, exchange best practices, address professional and development needs, and strives to be influential in setting the agenda for the effective use of information management to improve health and healthcare in Canada.

\section{CCF: COACH Clinician Forum}

This forum is a vital, multi-disciplinary, professional community supporting clinician engagement in HI, providing opportunities for clinicians to dialogue on emerging topics and providing valuable clinical input into the mission of $\mathrm{COACH}$.

\section{CTF: Canadian Telehealth Forum}

$\mathrm{COACH}$ is the voice for telehealth and the Canadian telehealth community and promotes and supports the integration of telehealth and electronic health record (EHR) capabilities through the education, networking and professional development services of CTF. This is based on the vision of telehealth and $\mathrm{HI}$ professionals playing critical roles in transforming the healthcare system and providing care at a distance, to meet growing patient demands.

\section{eHIP: Emerging Health Informatics Professionals Forum}

This forum supports professionals in the first five years of their HI careers by providing engagement with industry leaders, networking think-tank and résumé-building opportunities and career development tools. The related LinkedIn Group, COACH Emerging Professionals in Health Informatics, is a thriving social media resource. 
Practices

\section{eSafety}

Today's e-Health solutions ensure healthcare providers have accurate, up-to-date information for making treatment decisions and are increasingly important to improve patient safety. At the same time, health software implementations are inherently more complex and can inadvertently introduce patient safety risks. $\mathrm{COACH}$ is leading collaborative work with other related organizations to bring leading practices, guidelines, education and information to the forefront with the goal of protecting patients against harm throughout the development, implementation and use of e-Health systems. These initiatives are rooted in the 2013 eSafety Guidelines, designed to help public and private sector organizations bring safer e-Health solutions and health software to use across the healthcare system. By grounding accountability, safety culture, risk management, human factors engineering, incident response and reporting and safety case evidence and declarations, in internationally accepted HI standards and aligning with other patient safety practices, these Guidelines provide a means to enhance our confidence and trust in health IT. Related activities include establishing an agreement for jurisdiction-wide availability of the eSafety Guidelines in Alberta, the Northwest Territories and Ontario. (See Privacy \& Security and the Protection of Health Information below for $\mathrm{COACH}$ jurisdictional licensing program information.)

\section{Privacy \& Security and the Protection of Health Information}

COACH's Guidelines for the Protection of Health Information was first authored in 1989, fully published in 1995 and the first online edition was released in 2004. The main edition is the largest and most comprehensive health information privacy, security and confidentiality resource for the HI community across Canada and is considered useful in the international HI community. It is the up-to-date reference textbook for healthcare privacy, security and confidentiality. The latest edition covers emerging privacy and security issues such as social media, hybrid records and telehealth, and includes a new section on First Nations OCAPTM principles. The Guidelines provide a "best practices" approach beyond legislation which link to ISO standards and provide strategies for implementation. This resource provides HI professionals with the framework needed to minimize risk, maximize integrity and protect privacy for all personal health information and continues to reflect the realities and evolving requirements of the HI industry as major initiatives and implementations increase use of the EHR.

$\mathrm{COACH}$ also issues supplementary special editions of the Guidelines focusing on specific subject areas or audiences: Access Audits for EHRs (2014), a unique audit and logging resource; Patient Portals (2014), focusing on the distinct issues with secure, controlled computerized pathways between a patient and his/her health information; and Putting It into Practice (2013), assisting healthcare providers in the complex decision-making around setting up an EMR in a community setting.

$\mathrm{COACH}$ offers a vital program to provide assistance to provincial and territorial jurisdictions across Canada charged with the implementation of privacy legislation. The program provides for the purchase of a "license" by a jurisdiction to use the Guidelines content for the implementation of its own protection of health information program through the development of policies, controls, resource information and training programs for all those responsible in that jurisdiction - employees, contractors, physicians, pharmacists, etc. International jurisdiction licenses for the Guidelines are also available.

\section{$\mathrm{COACH}$ is proud to please with organizations such as:}

Canada Health Infoway

www.infoway-inforoute.ca

Canadian Institute for Health Information (CIHI)

www.cihi.ca

Canadian Nursing Informatics Association (CNIA)

www.cnia.ca

Canadian Health Information Management Association (CHIMA)

www.echima.ca

Canadian Medical Association

www.cma.ca

Canadian Healthcare Association

www.healthcarecan.ca

Information Technology Association of Canada (ITAC)

http://itac.ca/

Healthcare Information and Management Systems Society (HIMSS)

www.himss.org

HISA

www.hisa.org.au

\section{Information}

COACH: Canada's Health Informatics Association

11th Floor, 151 Yonge Street

Toronto, Ontario Canada M5C 2W7

Phone 647-775-8555

Toll free (in Canada) 18882538554

E-mailinfo@coachorg.com

www.coachorg.com

Facebook: (facebook.com/COACHORG)

Twitter(@COACH_HI)

YouTube

LinkedIn COACH Company Page \& Groups:

1. CPHIMS-CA

2. $\mathrm{COACH}$ Emerging Professionals in Health Informatics

3. CHIEF: Canadas Health Informatics Executive Forum (Members Only) 


\section{Biomedical and Health Informatics Activities in the United States}

\author{
AMIA - Informatics Professionals. Leading \\ the Way.
}

AMIA represents over 5,200 healthcare professionals, students, informatics researchers, practitioners and thought-leaders in biomedicine, healthcare and science. AMIA addresses challenges across the continuum of the health ecosystem - consumers and patients, healthcare providers and care delivery systems, population and public health, and basic and clinical research with the ultimate goal to advance better health, better healthca$\mathrm{re}$, and improved efficiency through the use of informatics and information technology.

\section{5-2020 Strategic Plan:Working Together to Transform Health and Healthcare}

Over the last 35 years, the use of informatics to inform an understanding of health and decision-making has grown exponentially thanks to the expertise and hard work of AMIA members. Today, informatics as a profession is at a tipping point. No longer is it just a special skill-a "knack" for using data. Informatics is a full-fledged career path, and the key for realizing the current goals of healthcare reform.

That's why AMIA introduced a new five-year strategic plan - to guide the organization and its members into the next era of informatics. We've worked over the last few years to elicit insights and input from AMIA members - both formally and informallyand applied it in developing the plan. As consumers across the health and healthcare spectrum push for better outcomes, lower cost and improved value, now is our collective opportunity to expand and deepen the role of informatics in transforming health and healthcare.

The strategic plan focuses on three core directives that matter most to members and leadership:

\section{Advancing Professional Growth for Our}

Members: To support the current and next generation of informatics professionals, we're at the forefront of professional education and training. From certification to leadership training, AMIA is committed to professional growth and multidisciplinary, inter-professional informatics leadership throughout our careers.
2. Creating Impact in Health and Healthcare: To improve health in the United States and globally, we're engaging with policymakers and other thought leaders to holistically improve health and healthcare with use of informatics' science, research and practice. By engaging directly with legislators and providing access to global innovation events, AMIA is devoted to being the go-to thought leader and convener for the field.

3. Enhancing Leadership for the Profession: To strengthen the informatics field, we're enhancing the ability of AMIA to serve as the leading voice for informatics professionals. By growing the capacity of the organization and expanding membership, every member will be supported with a robust organization that is nimble in serving evolving needs.

We invite our international colleagues to get involved - connect, learn, grow, lead - and bring on the next era in informatics.

\section{Advancing Professional Growth for Our Members}

AMIA enhances our members' abilities to lead, transform, and improve care through excellence in the practice of informatics, basic and applied informatics research, and education and training of informatics professionals. Some of these program highlights include AMIA events and publications.

\section{Joint Summits on Translational Science}

AMIA's Joint Summits on Translational Science continue to represent the best opportunities for networking with others in the translational bioinformatics (TBI) and clinical research informatics (CRI) communities. New for 2016 was the "Implementation Track," which features sessions focusing on the bridge between clinical research informatics and translational informatics. These sessions were of particular interest to those researchers and organizations committed to advancing the translation of discovery into real-world settings.

The Joint Summits served as the primary forum to connect with leaders in the field of informatics who are advancing translational science at the nexus of bioinformatics and clinical research. The theme of the 2016 Joint Summits was driving discovery and dissemination of precision medicine to improve patient and population health outcomes. The meeting brought together translational scientists, data scientists, informatics researchers and practitioners from academia, industry, government and non-profit sectors to share knowledge and best practices, and to forge collaborations across boundaries.

Led by Nicholas Anderson, Paul Harris and Subha Madhavan, the program offered exciting and informative panels and attracted over 600 individuals. To see more about the Summits, visit www.amia.org/jointsummits2016

\section{iHealth}

In May, AMIA hosted the third iHealth conference in Minneapolis, Minnesota. iHealth is about applied clinical and operational informatics and is specifically tailored for clinicians that use informatics tools in the clinical workplace. The conference demonstrated how informatics principles are currently being applied to information systems within health care delivery organizations to increase quality, reduce costs and enhance serviceswith the ultimate goal of transforming the care delivery experiences of patients.

New at iHealth 2016 was a call for participation focused around five topics that delivered a blend of contributed and invited preconference workshops, keynote talks, presentations, panels, interactive discussions, and poster presentations.

- Analytics and the Learning Health System

- Patient Engagement Strategies

- Health Policy impact on IT Strategy

- Interoperability and Informatics Infrastructure

- Payment Reform and Value-based Purchasing

Through program committee planning and contributions by "boots-on-the-ground" practitioners, clinical informatics physicians, nurses, pharmacists, and other practitioners fostered collaboration with networking among individuals, organizations, and Health IT industry in a flexible and organic way.

To see more about iHealth, visit www. amia.org/ihealth2016

\section{InSpire 2016}

InSpire is a new conference, born from the 10-year experience with the Academic Forum Annual Conference, to convene, share, and learn about state-of-the-art approaches and best practices in education, research, and training within the academic informatics community. The InSpire conference expands the forum community to support the current and next generation of academic and educational informatics professionals. 
The goal of AMIA's InSpire 2016 is to support innovative approaches in informatics education for research and practice across health professions education and the biomedical sciences. Participants learn how programs are supporting the next generation of science in informatics, are integrating research and academic experiences in progressive ways and moving toward shared didactic content using MOOCs and other innovative strategies. Students are involved in hands-on learning with their teachers integrating practical experiences into courses that will serve them as they hope to excel at their career. It is a dynamic time in informatics research and education! Topics will include:

- Accreditation and Certification Specialists

- Clinical Informatics Fellowship Program Directors and Coordinators

- Data Science and BD2K

- Emerging Faculty

- Health Informatics Educators

- Informatics Curriculum Developers

- International Educators

- Research Supervisors and Coordinators

- Workforce Strategists in Government and Industry

InSpire 2016 includes a blend of contributed and invited workshops, keynote talks, presentations, panels, interactive discussions, poster presentations, and networking. The conference will be home to business meetings of the Academic Forum and its member Communities. The AMIA Academic Forum has co-located its annual meeting with the National Library of Medicine (NLM) Informatics Training Conference June 27-28 with cooperation from the Ohio State University Department of Biomedical Informatics.

To see more about InSpire, visit www.amia. org/2016-academic-forum-annual-conference

\section{Annual Symposium}

AMIA hosts the premier informatics meeting in the U.S. The 2015 Scientific Program Committee, led by Christoph Lehmann, worked diligently to create compelling content, but the heart of the meeting is found in the connections and interactions of members and attendees. More than 2,300 members, registrants and exhibitors experienced AMIA 2015. This year the AMIA Twitter community included 1,214 participants generating more than 9,500 \#AMIA2015 tweets and more than 13.5 million impressions.
Last year's meeting featured full-length papers, abstract presentations, and posters, panel discussions including didactic and interactive panels with extensive audience participation, cutting-edge policy presentations, keynotes, tutorials, system demonstrations, and pre-Symposium workshops.

We also continued support for the next generation of informaticians with the Student Paper Competition recognizing the best work from students from all computing, information science, and design disciplines and the Student Design Challenge which provided students with the opportunity to design a solution to a problem in informatics. For the second year, AMIA 2015 included dedicated presentations, educational activities, and networking events for high school students and high school teachers participating in educational and research partnerships with biomedical informatics researchers across the United States.

The 2016 Annual Symposium is November 12-16 in Chicago, Illinois. We hope you will join us! www.amia.org/amia2016

\section{JAMIA}

In 2015, JAMIA continued to provide members and subscribers with the best in biomedical and health informatics publishing. Lucila Ohno-Machado and the JAMIA Editorial Board published a special issue on person generated health and wellness data as well as interactive systems for patient-centered care to enhance patient engagement.

A highlight of the 2015 volume year was the article, "Birth month affects lifetime disease risk: a phenome-wide method". The article, featured as an unlocked editor's choice article, was featured in Time, NPR and hundreds of news outlets was downloaded over 207,000 times. Read it today at http:// jamia.oxfordjournals.org/content/22/5/1042.

AMIA also published a report of the empaneled EHR-2020 Task Force on the status and future direction of EHRs. The report featured recommendations in four key areas that include simplifying and speeding documentation, refocusing regulation, increasing transparency and streamlining certification, and fostering innovation. The report is also available for free on the JAMIA website at http://jamia. oxfordjournals.org/content/22/5/1102.

\section{Applied Clinical Informatics}

In late-2015, the Applied Clinical Informatics Journal became an official journal of AMIA along with its continued affiliation as an official journal of IMIA. As part of the collaboration with the ACI publisher, AMIA gains three seats on the ACI Journal editorial board and peer-reviewed publishing rights for AMIA policy papers and statements of interest to the broader ACI community, as well as promotional opportunities for AMIA meetings, educational products and services. The collaboration also offers ACI subscriptions as part of the AMIA membership benefit package for members, including students.

The addition of the ACI Journal to AMIA's stable of educational products and services is part of the organization's ongoing professional leadership in and for the support of the applied clinical informatics community. The ACI Journal is another vehicle endorsing AMIA as an authoritative, current, practical voice in the clinical informatics domain.

For more information, see https://aci. schattauer.de/

\section{Creating Impact in Health and Healthcare}

AMIA is the most influential voice for the effective and innovative use of informatics to improve health. One of these program highlights include the policy meeting.

For the last nine years, the AMIA Policy Invitational has served as a unique platform to inform legislative, regulatory, and policy development. During the 2015 meeting led by Tom Payne on the topic of "Unlocking the Potential of Electronic Health Records: How Policymakers Can Impact the On-going Evolution of EHRs", participants had thought-provoking discussions that articulated the role of biomedical and health informatics in developing next-generation federal policies and research priorities. The themes of the invitational built on the work of the AMIA EHR-2020 Task Force, and what emerged was a set of recommendations focused on the tensions created by multiple stakeholders who wish to use the EHR for (1) data capture for the point of care; (2) population health management and (3) research / innovation. Later in 2016, AMIA expects to publish an accounting of recommendations meant to ease these tensions, and provide a research agenda for the ongoing evolution of EHRs.

AMIA is also actively engaged with the US federal government's plans to transition Medicare Fee-For-Service payment system to one that is predicate on value. In order to accomplish this, informatics experts will play an ongoing role with federal officials to 
help determine the best use of IT to manage care, and help measure quality in an electronic world. Currently policies are in development along a host dimensions resulting from the Medicare Access and CHIP Reauthorization Act, also known as MACRA.

Finally, AMIA participated in a national discussion over how to modernize the federal protections of human subjects research, also known as the Common Rule. Originally developed in 1991, these protections could not account for recent developments in computing capacity, storage and other technological advances. Federal regulators knew that to capitalize on the promise of precision medicine and related innovations, the Common Rule must be overhauled. AMIA expects finalization of proposed changes in mid-2016.

\section{Enhancing Leadership for the Profession}

AMIA will strengthen our informatics leadership, membership, and our financial future, strengthening our identity while preserving the value of AMIA. Some of these program highlights include AMIA education, certification and community networking.

\section{0x10 Programs}

AMIA believes that strengthening the breadth and depth of the biomedical and health informatics workforce is a critical component in the transformation of the healthcare system. AMIA is committed to the education and training of a new generation of clinical, public health, research, and translational bioinformatics informaticians. AMIA's 10x10 utilizes curricular content from existing informatics training programs and other AMIA educational initiatives with a special emphasis toward those programs with a proven track record in distance learning. The content provides a framework but also covers plenty of detail, especially in areas such as electronic and personal health records, health information exchange, standards and terminology, and health care quality and error prevention.

AMIA also offers an internationally-focused variation of the successful $10 \times 10$ program called i10x10. Courses qualifying for the i10x10 program should be endorsed by a local or regional IMIA member society. Global partners interested in offering courses and learning more about $110 \times 10$ should contact AMIA (no application fee is required for submission of a proposal).

To see more about 10x10, visit www. amia.org/education/10x10-courses

\section{Advanced Health Informatics Certification Update}

The AMIA Board of Directors continued its commitment to strengthening the profession of informatics by creating a way for advanced practitioners to demonstrate their expertise by establishing an advanced certification in health informatics that meets the needs of individuals from diverse health professions and is equivalent in rigor to the clinical informatics medical subspecialty. The AMIA Board of Directors endorsed recommendations from an interdisciplinary work group that 1) defined the scope of certification and recommended the name Advanced Health Informatics Certification (AHIC) to identify the certificate; 2) recommended approaches for developing health informatics Core Content; 3) proposed rigorous quantitative and qualitative eligibility requirements intended to span diverse health informatics professions; and 4) empowered the AMIA staff to identify strategies to create a certifying entity to lay the groundwork for implementing AHIC. AMIA will initiate process for finalizing Core Content that will serve as the basis for the AHIC high-stakes examination and publish proposed eligibility requirements for potential applicants of the AHIC in 2016.

\section{Membership Communities}

With over 5,200 members, communication and collaboration among AMIA members is key to advancing the goals of the organization and its membership, and to improving the profession itself. AMIA supports networks that serve as channels through which current members can exchange information on specific areas of biomedical and health informatics with colleagues and become involved in the development of positions, white papers, programs and other activities that benefit the informatics community. These are known as Working Groups and each has an online community that facilitates interaction among members.

Within AMIA, there are three other significant communities - the Academic Forum and the Industry Advisory Council and the American College of Medical Informatics.

The Academic Forum exists to serve the needs of post baccalaureate biomedical and health informatics training programs. It offers a place for academic leaders and faculty from nearly 60 programs to discuss national research initiatives in informatics and its roundtable addresses objectives for education and research by facilitating collaboration across academic units. Participants focus on a range of issues important to faculty such as management, promotion criteria, recruitment, models of success in building informatics programs, salary scales, and advocacy within academic environments. Forum members plan their annual meetings and participate in task forces that address important educational and certification/accreditation issues that are related to the clinical informatics developments.

The Industry Advisory Council plays a unique and powerful role in healthcare, academia, and product research and development. As the primary convener of some of the most influential informatics meetings in the healthcare industry, our corporate members engage directly with established and emerging leaders in informatics. Through the Industry Advisory Council, corporate members serve as counsel to and as an influential feedback channel for board initiated collaborations and investigations. Active participants in the IAC have played a vital role in advancing public policy while deepening their reach in the informatics community.

The American College of Medical Informatics is a college of elected fellows from the U.S. and abroad who have made significant and sustained contributions to the field of biomedical and health informatics. It is the center of action for a community of scholars and practitioners who are committed to advancing the informatics field. The College exists as an elected body of fellows exceeding 400 in number within AMIA, with its own bylaws and regulations that guide the organization, its activities, and its relationship with AMIA.

In 2015, ACMI selected Dr. Jan H. van Bemmel as the recipient of the 2015 Morris F. Collen Award of Excellence. Dr. van Bemmel is Professor and Chairman of Medical Informatics at the Faculty of Medicine and Health Sciences of Erasmus University, Rotterdam.

\section{For more information}

AMIA

4720 Montgomery Lane, Suite 500

Bethesda, MD 20814, USA

Tel: +1 3016571291

Fax: +1 3016571296

E-mail:mail@amia.org

Website: www.amia.org

Twitter: @,AMIAinformatics

LinkedIn: Official Group of AMIA

Facebook: American Medical Informatics Association 